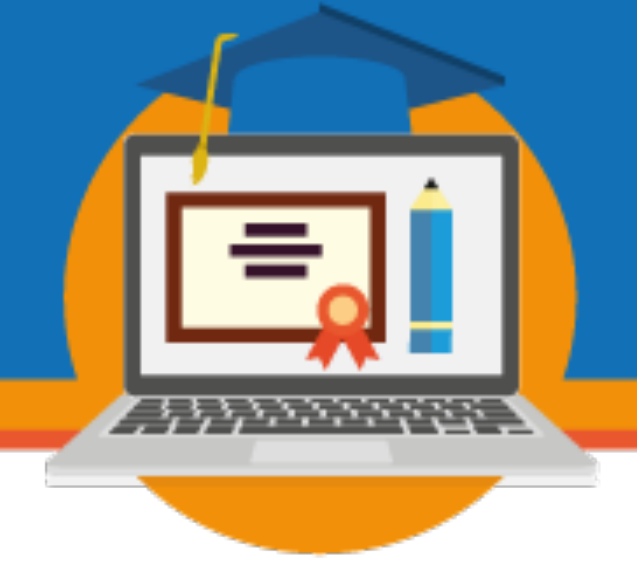

\title{
EDUCAÇÃO HÍBRIDA NA FORMAÇÃO DOS INDÍGENAS A’UWẼ UPTABI (XAVANTE): O CONTEXTO DO CURSO DE PEDAGOGIA EAD IE/NEAD/UFMT/UAB
}

\author{
Maria Aparecida Rezende \\ Universidade Federal de Mato Grosso \\ rezemelo@gmail.com \\ Glauce Viana de Souza Torres \\ Universidade Federal de Mato Grosso \\ glauce.ufmt@gmail.com
}

Eixo 5: Educação híbrida: uma tendência na educação superior

\begin{abstract}
Resumo: O artigo realiza diálogo acerca da Educação Híbrida no desenvolvimento formativo dos estudantes indígenas A'uwẽ uptabi (Xavante) no contexto do Curso de Pedagogia EaD/UFMT. Os dados deste artigo advêm de pesquisas bibliográficas, documentais e observações pedagógicas realizadas no AVA do curso em tela. A análise potencializa assertivas que há prática formativa da educação híbrida ao longo do desenvolvimento do curso, e que a história do curso foi reivindicando hibridez para que ele se sustentasse com qualidade, diante dos contingenciamentos sofridos na educação pública, sobretudo a educação a distância. Como forma de resistência, o ensino superior indígena mantém-se enquanto demanda nacional, e a $\mathrm{EaD}$ com subsídio da educação híbrida assume papel de destaque para o alcance do ensino superior dos indígenas.
\end{abstract}

Palavras-chave: Educação a distância. Educação online. Educação híbrida.

\section{Introdução}

O Curso de Licenciatura em Pedagogia, modalidade de Educação a Distância (EaD), é ofertado pelo Instituto de Educação - IE na Universidade Federal de Mato Grosso - UFMT, Núcleo de Educação Aberta e a Distância - NEAD e pelo Sistema Universidade Aberta do Brasil - UAB. A partir desse momento, o curso será referido como Curso de Pedagogia EaD.

O marco referencial do primeiro Projeto Pedagógico (PP) de Pedagogia no IE/UFMT na modalidade presencial como na educação a distância, traz a expectativa de atendimento 
formativo de professores que atuavam na educação básica sem o ensino superior, denominados de professores leigos, fato presente na discussão em tela com os professores indígenas do curso de Pedagogia turma 2017. Nesse sentido a relevância social da formação amplia em dimensões imensuráveis, especialmente no atendimento das comunidades indígenas que a universidade pública consegue alcançar para além dos seus muros, em eu destacamos: aldeias, quilombos, assentamentos e outros grupos invisibilizados de direito. Todavia os 27 anos de oferta do Curso de Pedagogia IE/Nead/UFMT, com aproximadamente 6.000 formados, ainda necessita de políticas públicas educacionais que culmine no atendimento de diferentes grupos sociais em situação de vulnerabilidade social, na situação de ausência do financiamento Capes, gestado pelo sistema UAB.

Alguns princípios ancoram esse curso desde sua origem, como o abandono à disciplinaridade optando pela formação interdisciplinar. (PPC, 2012). O curso visa trabalhar com uma formação em que as finalidades educacionais sejam interconectadas com as dimensões sociais, interpessoal, pessoal e profissional.

Ao longo do curso os estudantes vão desenvolvendo momentos de aprendizagem e ensino híbrido, também chamado como blended learning, que é essa combinação de práticas pedagógicas com ensino presencial e ensino a distância. São momentos de ensino e aprendizagem que o estudante estuda sozinho, online, offline e momentos de estudos em grupo, valorizando a interação entre estudantes e estudantes, estudantes e docentes. Desta maneira ocupamos da definição original de Ensino Híbrido por seus criadores que estabelecem [...] é um programa de educação formal no qual um aluno aprende por meio do ensino online, com algum elemento de controle do estudante sobre o tempo, o lugar, o modo e/ou o ritmo do estudo, e por meio do ensino presencial, na escola. (BACICH; TANZI NETO; TREVISANI, 2015, p. 52)

Nessa hibridez é fundamental que a formação não desconecte com a realidade social dos seus educandos. Nesse sentido, vale a afirmação de que, “[...] o saber científico somente pode ter sentido educativo quando está a serviço do desenvolvimento humano em suas vertentes pessoais e sociais" (ZABALA, 2002, p. 58). Todavia, o curso adota a filosofia que os indígenas 


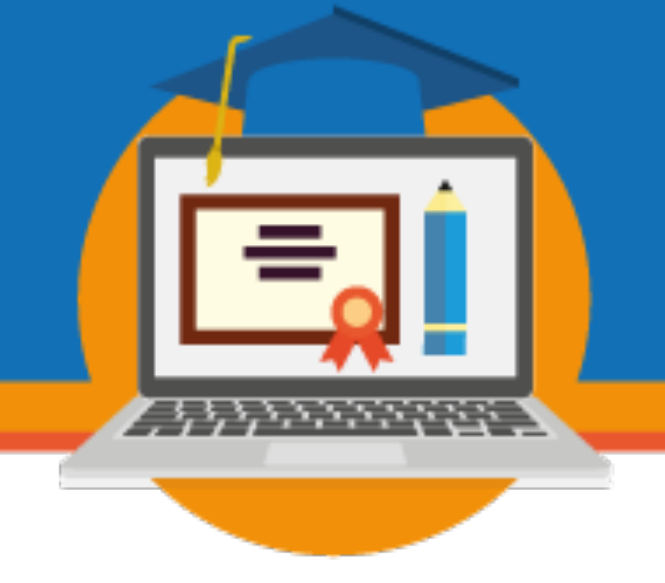

não deixam fora de sua vida, que somos apenas uma espécie e por isso é essencial conciliar a vida humana a todas as outras vidas presentes no planeta terra. Ao concebermos esse entendimento, tecemos fios dialógicos acerca do ensino híbrido e as potencialidades na formação docente, seja na modalidade a distância ou presencial.

\section{Fios condutores da formação docente indígena: entendimento e realidades da sala de aula A'uwẽ uptabi - Xavante}

Ao abordarmos as questões relativas à formação docente estamos nos propondo a dialogar sob recorte da formação de professoras pedagogas e professores pedagogos, especialmente a dimensão dos saberes e conhecimentos dos professores relacionados a essa formação, sobretudo a indígena. Isso requer um entendimento de que os professores buscam os saberes institucionalizados, mas também essas instituições devem considerar os saberes deles nessa formação, e é nesse contexto que o curso de Pedagogia EaD apresenta intencionalidade formativa.

A contribuição dos fios condutores propostos por Tardif (2002) é essencial para refletirmos a qualidade que o curso, ainda pode alcançar juntamente com outros que aceitaram o desafio da educação indígena. O primeiro fio condutor é saber e trabalho “[...] o saber dos professores deve ser compreendido em íntima relação com o trabalho deles na escola e na sala de aula" (TARDIF, 2002, p. 16-17). Isso mostra a relação do professor com sua escola, com seus estudantes, com a comunidade que se relaciona com essa escola, com as condições de recursos e todos os enfrentamentos das situações diversas que vão aparecendo no cotidiano desse trabalho docente.

Essa discussão interessa para o curso em estudo, pois aos estudantes consideramos a relação “[...] o saber à pessoa do trabalhador e ao seu trabalho, àquilo que ele é e faz, mas também o que foi e fez, a fim de evitar desvios em direção à concepções que não levem em conta sua incorporação num processo de trabalho" (TARDIF, 2002 p.17). Os estudantes do curso advêm das cidades do interior, o que já diferencia da capital, da zona rural e das comunidades indígenas. Por isso, o respeito à dimensão cultural e modos de ser e viver. Os 
estudantes A'uwẽ uptabi os saberes/conhecimentos da academia devem ser complementos nessa formação de interação com sua educação étnica que também contribuirão para a formação de professor para seu grupo social onde vive. Assim deve evitar que seja "produzido e modelado" pelo trabalho da formação escolarizada sem levar em conta seu modo de ser e viver.

O segundo fio condutor é a diversidade do saber. É um saber que está ligado a natureza social, pois contém conhecimentos e usa saber-fazer. O terceiro fio condutor temporalidade do saber é afirmar que além de plural o saber dos professores é também temporal, uma vez que é constituído no contexto de uma história de vida e de uma carreira profissional. Isso gera a ideia que ensinar supõe aprender a ensinar, ou seja, é preciso adquirir o domínio à realização do trabalho docente (TARDIF, 2002).

O penúltimo fio condutor diz respeito a experiência de trabalho enquanto fundamento do saber. "Ensinar é mobilizar uma ampla variedade de saberes, reutilizando-os no trabalho para adaptá-los e transformá-los pelo e para o trabalho" (TARDIF, 2002, p. 21). Essa experiência de trabalho é a reflexividade acerca do que se sabe fazer e vem fazendo ao longo da sua própria prática profissional. Essa discussão lembra as práticas da profissão de docência dos professores Xavante, ali percebia-se que os saberes adquiridos eram uma mistura dos exemplos de professores que ele tinha nas escolas dos salesianos, mas estava marcante a presença do educador Xavante que insistentemente ensina, sem preocupar-se com o tempo que se leva para aprender a desenvolver as atividades para ser um bom homem xavante e uma boa mulher xavante. A preocupação é com a aprendizagem, pois aquele conhecimento ensinado é levado para a vida toda de maneira singular.

Por fim, o último fio condutor "saberes e formação de professores" é repensar a formação dos professores levando em conta suas realidades específicas do seu trabalho cotidiano. Pode-se dizer, da sua vivência cotidiana, pois como foi abordado não se separa a história de vida do professor de sua profissão. E esse tem sido o desafio das universidades e de todos os cursos de formação de professores, ou seja, buscar o equilíbrio entre os conhecimentos produzidos pelas universidades a respeito do ensino e os saberes desenvolvidos nas práticas do 
cotidiano dos professores. É costume separar o conhecimento científico (considerado puro) do "conhecimento cotidiano elaborado" como nominou Tardif (2002).

Os trabalhos acadêmicos até momento produzidos pelos estudantes A'uwẽ uptabi nos núcleos de aprendizagem previstos no PP, especialmente os percursos, há uma média de 7 (sete) correções em cada trabalho, compõe o movimento da sala de aula virtual e presencial dos Xavantes. Retrata que as universidades não podem ignorar que os estudantes fazem parte de uma realidade diferente e que é essencial buscar o elo entre os saberes desses estudantes produzidos em suas práticas cotidianas com os saberes ensinados nas universidades para construir um novo saber de acordo com um trabalho interativo, como afirma Tardif op cit. A partir desse entendimento apresentamos algumas práticas pedagógicas híbridas construídas no curso de Pedagogia IE/Nead/UFMT.

\section{Práticas pedagógicas híbridas desenvolvidas no Curso de Pedagogia Nead/IE/UFMT}

O curso de Pedagogia EaD é desenvolvido na plataforma moodlle, mas possuí atendimento de 40 horas semanais presencial nos polos, por meio das orientadoras acadêmicas. Estas são professoras efetivas, licenciadas, e com atuação na educação básica, cedidas pela Prefeitura Municipal em contrapartida a UFMT/IE como parte dos investimentos na educação. A função das orientadoras é assumir a mediação da aprendizagem no polo de atendimento presencial.

Em cada disciplina prevista na matriz curricular do curso há elaboração de um documento denominado "guia didático" que contempla as unidades de estudos do Plano de Ensino docente, com atividades organizadas em um cronograma/semanas de estudo. O docente explora as diferentes ferramentas do AVA para melhor desenvolvimento do ensino aprendizagem a distância, considerando todo conteúdo elaborado no material didático impresso- fascículo, em cada uma das disciplinas. As atividades são proposta de maneira síncrona e assíncrona.

No Ambiente Virtual de Aprendizagem, as atividades são disponibilizados em arquivos digitais que podem remeter para links que direcionam aos filmes, documentários ou mesmo 
leitura de artigos que complementam os estudos naquela área. Os docentes acompanham o desenvolvimento dos estudantes por diversos meios: leitura dos textos produzidos por eles (envio de arquivos), fóruns, web conferência, chat e outras ferramentas comunicacionais.

Atualmente a educação a distância conta com diversas maneiras de educação online e diferentes possibilidades. A inovação no ambiente de aprendizagem ao encontro da cibercultura foi o uso do Chat, utilizado nas disciplinas do terceiro núcleo de estudos, sendo elas: Mundo Social: Ciências Sociais História I e II e Mundo Social: Ciências Naturais I.

O Chat usado no curso como interface do AVA para a comunicação síncrona, ou seja, mensagens instantâneas entre professores formadores, orientadoras e acadêmicas. $\mathrm{O}$ curso faz uso deste como espaço de aprendizagens, assumindo uma função pedagógica. Os professores formadores são os moderadores, definindo antecipadamente a temática e a dinâmica das interações. A mediação dos professores formadores contempla iniciar o chat na data e horário definidos, conduzir as interações e encerrar a discussão. Os participantes acessam o chat e interagem em turnos alternados: pergunta ou contribuição; resposta do interlocutor; nova pergunta, assim sucessivamente, para garantir a continuidade e a progressão da temática.

Para Santos (2019'), a Cibercultura é a cultura contemporânea mediada pelas tecnologias digitais em rede, e são de usos e desenvolvimentos científicos, enfim os usos que os sujeitos culturais fazem dessa tecnologia. Destaca que não se pode colocar as tecnologias na centralidade, mas sem elas não há cibercultura. Ainda afirma que a educação online é um fenômeno da cibercultura.

As tecnologias fazem parte da infraestrutura das sociedades, isso historicamente. As tecnologias são todos os meios de artefatos, modo de se fazer e de construir conhecimento. Tudo que utilizamos como extensão do nosso corpo, da nossa inteligência, da nossa capacidade de se comunicar, tudo isso faz parte das tecnologias. Atualmente se vive numa sociedade da

\footnotetext{
${ }^{1}$ A professora Edmea Oliveira dos Santos (UFRRJ) em palestras proferidas no ESUD- XVI Congresso Brasileiro de Ensino Superior à Distância e V Congresso Internacional de Educação Superior a Distância: responsabilidades e Desafios para a Consolidação da EaD, realizado em Teresina - Piaú nos dias 26 a 29 de novembro de 2019.
}

III SEMINÁRIO DE EDUCAÇÃO A DISTÂNCIA 


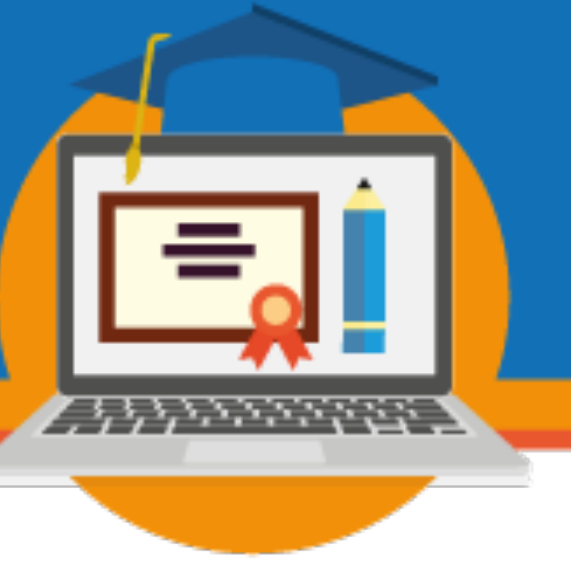

informação que é matéria prima, circula em rede e as tecnologias digitais causam mudanças e transformações profundas nas relações humanas (SANTOS, 2019).

A cibercultura ensina que é preciso ressignificar práticas de educação a distância que já não fazem sentido, inclusive as que são limitantes e subutilizadas em termos de usos de tecnologias. Alguns cursos online subutilizam as tecnologias digitais repetindo as mesmas práticas das tecnologias dos modelos impressos. Ela enfatiza a educação online (SANTOS, 2019). "A cibercultura é a cultura contemporânea mediada por tecnologias digitais em rede no ciberespaço e nas cidades" (SANTOS, WEBER, 2018, p. 23). A educação online é um fenômeno da cibercultura que é a cultura mediada pela tecnologia em rede. É toda a produção humana quando damos sentidos a tudo que criamos.

\begin{abstract}
A educação online é uma modalidade de educação que pode ser vivenciada ou exercitada para potencializar situações de aprendizagem mediadas tanto por encontros presenciais, quanto a distância, caso os sujeitos do processo não possam ou não queiram se encontrar face a face; ou ainda situações híbridas, nas quais os encontros presenciais podem ser combinados mediados por tecnologias telemáticas (SANTOS, WEBER, 2018, p.24-25).
\end{abstract}

Todavia defendemos como Valente (2015), Alonso e Silva (2014) e outros pesquisadores de área de educação mediada por tecnologia, que a intencionalidade e planejamento pedagógico são imprescindíveis no processo formativo e que não adianta dar centralidade nos dispositivos tecnológicos. A emergência das várias formas de acessar a internet, e uma delas é carregar essa internet na palma da mão, por meio de um único dispositivo - smartfone- não substitui a importância do planejamento, e os resultados com os diferentes atores do processo formativo. Não importa o recurso, câmera fotográfica, câmera de vídeo, computador e tantos outros processos que se podem fazer uso em sala de aula, nenhum recurso isenta o papel dos professores no processo formativo da prática pedagógica. Dessa maneira apresentamos alguns elementos da aprendizagem hibrida vivenciada pelos A'uwẽ uptabi.

\title{
A aprendizagem hibrida dos acadêmicos indígenas $A^{\prime} u w \tilde{e}$ uptabi (Xavante).
}




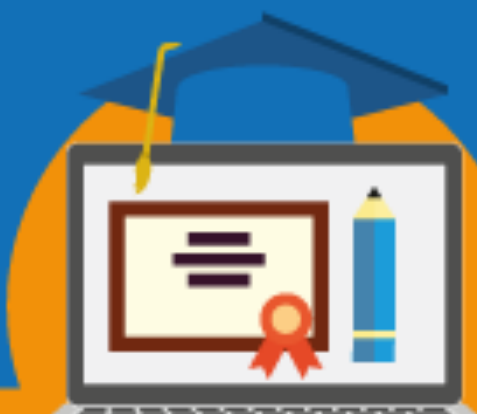

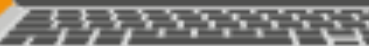
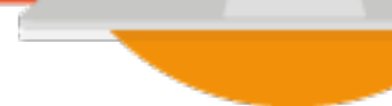

dificuldades financeiras para o transporte, hospedagem e alimentação das suas comunidades até o polo.

A educação híbrida se reafirma como solução diante das dificuldades de deslocamento, uma vez que [...] "criam oportunidades para a construção de seu conhecimento" (VALENTE, 2015, p. 15). Estudam por meio dos fascículos impressos nas aldeias realizam estudo dirigido, para posteriormente deslocarem aos polos para dirimir suas dúvidas. Somente no polo recebem mediação de aprendizagem com as orientadoras acadêmicas e as atividades que dependem da internet, tais como: consultas em bibliotecas digitais; participação de aulas por web conferência com os docentes; uso do Ambiente Virtual de Aprendizagem para postagem das suas atividades de envio de arquivo, participação em fórum, chat. Nesse sentido há uma combinação de estudos presencial e on line

Os acadêmicos indígenas participam do Programa Institucional de Bolsas de Iniciação à Docência (PIBID) em um esforço coletivo da equipe pedagógica do curso e Secretário de Educação de Canarana junto à Prefeitura para a vinculação dos acadêmicos no programa, uma vez que potencializa o exercício da docência nas aldeias e recebem a bolsa que é utilizada para subsídio no deslocamento aldeia /polo. O Pibid contribuí significativamente na diminuição da evasão.

A aprendizagem hibrida tem outros desafios. Os acadêmicos indígenas são falantes da língua A’uwẽe, língua falada em sua comunidade sem inserção da Língua Portuguesa e isso dificulta sua compreensão das tarefas propostas, todas nessa segunda língua que é a portuguesa. O curso não oferece intérpretes, nem docentes e nem as orientadoras falam sua língua, assim o entendimento é de que o problema não é deles, mas do curso que sente dificuldade para lidar com essas situações.

A conquista de inserção de povos indígenas no curso ocorreu por meio de ações coletivas desses povos para ter o direito de fazer cursos por meio da educação a distância, mas não deu tempo de preparar os cursos e assim fica a provocação da continuidade dessa proposta ser de fato acolhida pelos cursos de Educação a Distância nas universidades públicas. 


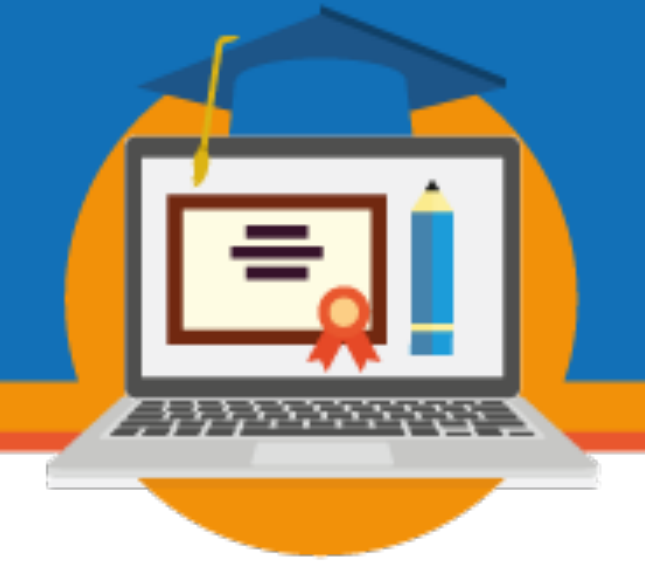

\section{Considerações Finais}

Com a intenção de realizar diálogos acerca das potencialidades e desafios Educação Híbrida na formação dos indígenas A'uwẽ uptabi (xanvante) no contexto do curso de Curso de Pedagogia, considerando as várias maneiras de interpretar a luz de outros referenciais teóricos, os elementos que compõem as informações coletadas ao longo do curso, é possível apontar algumas considerações, apresentando algumas outras que ficam para novas pesquisas.

Em relação à educação híbrida há evidências de atividades desenvolvidas durante o curso em suas áreas de conhecimento com momentos presenciais, online, offline e tarefas estendidas nas comunidades indígenas, outras na plataforma e outras no polo com a orientação das orientadoras acadêmicas, bem como pelos docentes da área. Além disso, todo um aparato de acompanhamento pedagógico e de gestão, desde as parcerias dos municípios envolvidos nos polos de Água Boa, Canarana, Juara e Primavera do Leste, as coordenações do curso, do NEAD, coordenadoras pedagógicas, orientadoras acadêmicas e da Secretaria de Tecnologia Educacional (Setec) da UFMT, frente aos contingenciamentos.

Desse modo, afirma-se que o curso apresenta em seu bojo uma educação online, offline e com propostas de ensino e aprendizagem híbridos. É preciso dizer mais, que a própria trajetória do curso e sua história foram reivindicando essa hibridez para que ele se sustentasse com qualidade na sua atuação no interior do Estado de Mato Grosso e em outro país como o Japão.

A segunda parte da discussão em tela trata do problema linguístico em curso. Os estudantes têm se empenhado para acompanhar os demais estudantes, falantes da língua portuguesa, porém necessita-se fazer duas observações que custam caro para o curso e tem sido 
uma pedra em seu calcanhar (parafraseando a pedra no calcanhar de Aquiles). A linguística e a educação étnica. O curso ainda se limita nesse atendimento, havendo necessidade de investimentos do poder público federal na formação indígena.

Ao serem indagados acerca da importância do curso para eles, todos afirmaram em reunião que precisam dele para ajudar a sua comunidade. A reunião foi realizada com eles, estudantes, caciques e lideranças confirmando que o curso é a esperança do aprendizado da língua portuguesa e da ciência dos waradzu (não indígenas) para facilitar a compreensão nas negociações entre a sociedade majoritária e eles. Por isso a educação escolar é importante e o curso contribuirá para esse apelo e demanda e, sobretudo a educação hibrida que assume pape de destaque para o alcance da formação no ensino superior dos indígenas. Como afirma Valente (2015, p.15), no Ensino Híbrido: “A responsabilidade da aprendizagem agora é do estudante, que assume uma postura mais participativa, resolvendo problemas, desenvolvendo projetos", em nosso caso, projetos nas aldeias.

Diante de todas as intempéries que o curso vem enfrentando fica o desejo de construir uma proposta para o novo PC já em andamento para novas turmas, encaminhamentos que possam minimizar o problema linguístico, cultural, porém o financeiro dependerá das políticas públicas brasileiras para uma educação a distância que possa ser desenvolvida com qualidade de uma educação online, híbrida com possibilidades dos usos das tecnologias digitais pelos estudantes indígenas de acordo com as demandas do curso. O educador brasileiro que se preocupou com os oprimidos da história "o que a invasão cultural pretende, entre outras coisas, é exatamente o dominado" (FREIRE, 2013, p. 28-29).

O curso vai em direção contrária a essa afirmação e desejos do dominador. O que se quer é uma formação com liberdade de usos e costumes das línguas e respeito à educação e cultura dos povos indígenas e que suas ciências sejam contribuidoras para a qualificação das ciências oferecidas pela educação escolar para que as tornem mais tolerantes e humanizadas para acolher todas as diferenças no cotidiano da vida. 


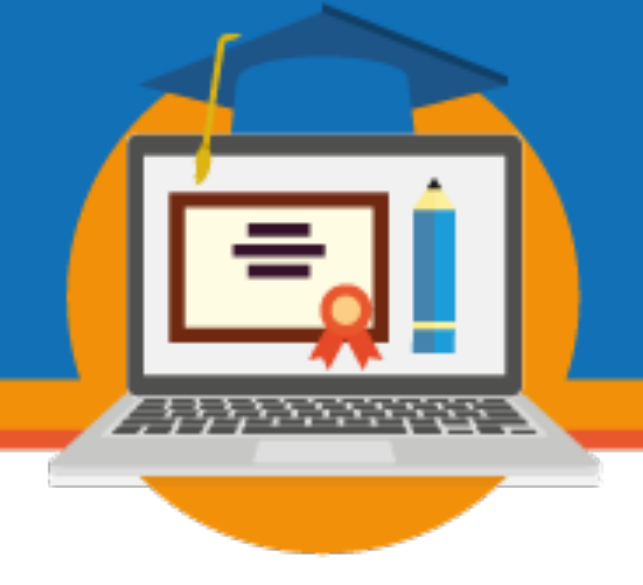

\section{Referências}

ALONSO, Katia Morosov; SILVA, Danilo Garcia. Trabalho docente, educação a distância e as TIC: entre a excitação e o sobre trabalho. Linhas Críticas, Brasília,v. 19, n. 40, p. $561578,2014$.

BACICH, Lilian; TANZI NETO, Adolfo; TREVISANI, Fernando de Mello. Ensino Híbrido: Personalização e tecnologia na educação. In: BACICH, Lilian; TANZI NETO, Adolfo; TREVISANI, Fernando de Mello (orgs.). Porto Alegre: Penso, 2015, p. 47-65.

FREIRE, Paulo. Pedagogia da tolerância. Organização, apresentação e notas Ana Maria Araújo Freire. 2 ed. Rio de Janeiro: Paz e Terra, 2013.

MORAN, Jose. Metodologias ativas e modelos híbridos na educação. In: YAEGASHI, Solange e outros (Orgs). Novas Tecnologias Digitais: Reflexões sobre mediação, aprendizagem e desenvolvimento. Curitiba: CRV, 2017, p.23-35. http://www2.eca.usp.br/moran/wpcontent/uploads/2018/03/Metodologias_Ativas.pdf acesso dia 14/01/2020

PROJETO POLÍTICO PEDAGÓGICO DO CURSO. Licenciatura em Pedagogia Modalidade a Distância. Cuiabá: EdUFMT, 2012.

SANTOS, Edmea; CAPUTO, Stela Guedes. Diário de pesquisa na cibercultura: narrativas multirreferenciais com os cotidianos. Rio de Janeiro: Omodê, 2018.

SANTOS, Edmea; ROSSINI; Tatiana Stofella Sodré. Recursos educacionais abertos: desafios para a didática na cibercultura. In: SILVA, Marco; ORLANDO, Claudio; ZEN, Giovana (organizadores). Didática: abordagens teóricas contemporâneas. (Organizadores). Salvador: EDUFBA, 2019.

TARDIF, Maurice. Saberes docente e formação profissional. Petrópolis, RJ: Vozes, 2002. 
